\title{
Socio-Cultural and Societal Demands Influencing Pregnancy among HIV Positive Women in Kakamega County, Kenya
}

\author{
Isaac Maru, Rose Olayo, and Mary Kipmerewo
}

\section{ABSTRACT}

Globally, the number of women living with HIV who desire pregnancy has been increasing and little is known as what motivates them, with test and treat women accessing ART desiring pregnancy will increase. Kakamega County has been leading in the region on women living with HIV accessing antenatal services. Past literature in the subject matter failed to look at socio-cultural and societal factors influencing pregnancy among HIV positive women in Kakamega County, Kenya; a gap that informed this study. A descriptive cross-sectional research design was employed. The target population were women aged 18-49 years receiving their family planning services in sub-county hospitals in Kakamega County. Key informants were made up of health care workers at comprehensive care clinics. Purposive sampling was used to select 4 sub-county hospitals, systematic random sampling to select 319 known HIV positive women and 4 focus group discussions. Questionnaires focused on group discussions and key informant interviews were used to collect data. Data collected were entered into Statistical Package for Social Sciences version 25.0. Descriptive results were presented in proportionate tables. The results showed that age, education, employment status and parity influenced the desire for pregnancy among HIV positive women in Kakamega County. Society influenced the number of children a woman should have. The community held a negative perception of childless women, especially HIV positive women; the community members did not attach value and pride over the childless HIV positive women. The socio-cultural and societal demand on HIV positive women influenced pregnancy; however, there decreasing association, which meant that the society was $71 \%$ less likely to influence the number of children; the spouse was $63 \%$ less likely to influence pregnancy. In conclusion, age, education level, marital status parity and employment status, medical cover influenced pregnancy among the known HIV positive women in Kakamega County. Socio-cultural and societal demands were predictors of pregnancy among known HIV positive women in Kakamega County. The community should treat HIV positive women with respect and dignity, thus permitting them to continue their family legacy and sire children. It recommends that there is a need for the county government, department of health services to provide health education to the community on stigma reduction and discrimination meted on these women and negative perception of childlessness women in the society especially known HIV positive women. Further works on the myths and misconception that barrenness is blamed on women leaving men scot-free for the cloud to be the culprits of childlessness in the family.

Keywords: Cultural demand, family planning, HIV, pregnancy.
Submitted: October 6, 2021

Published: November 16, 2021

ISSN: 2593-8339

DOI: $10.24018 /$ ejmed.2021.3.6.1097

\section{R. Olayo}

Masinde Muliro University of Science and Technology, Kakamega, Kenya.

(e-mail: rolayo@mmust.acke)

I. Maru*

Masinde Muliro University of Science and Technology, Kakamega, Kenya.

(e-mail: maruisaac2015@gmail.com)

M. Kipmerewo

Masinde Muliro University of Science and Technology, Kakamega, Kenya.

(e-mail: kipmerewosoi@yahoo.com)

\section{INTRODUCTION}

The HIV scourge has increasingly affected women of childbearing age than any other population and category. It is biblical that both a man and a woman were given the responsibility of procreating; the death of a child naturally would demand the desire for another child [1]. Income and financial freedom are important for married couples especially HIV positive partners; it encourages WLHIV to pursue biological offspring for family continuity [2].
Education is the foundation of the overall knowledge among childbearing women and the necessities that comes with it. Lack of financial freedom has seen many WLHIV avoiding pregnancy [3]. Fear is a predictor of HIV positive women being reluctant to conceive to avoid possible transmission of HIV to a fetus [4], [5] state that the age, marital status, economic status and education level of the woman affects the fertility intentions. Reference [6] argue that not having a biological child is seen as a factor that influences HIV positive women to desire to get pregnant. Pregnancy is a rite 
of passage to womanhood, fertility test, identity and marital function [7] thus, women living with human immunodeficiency virus (HIV) desiring biological children is on the rise.

Culturally in Africa, one is not complete with no biological children of their own [8], and women living with HIV are not different when it comes to proving motherhood and finding their own family or own children. In sub-Saharan Africa, married women are burdened with the responsibility of bearing children and lack of it brings about cultural misunderstanding [9], [10]. stated that sexual partners, family, and significant others such as the extended family or neighbors affect the decision of women to get pregnant. The individual and societal factors appear to be major determinants of fertility desires among women living with HIV; community members being a factor to consider where the support and approval by the spouse and the community determined pregnancy [11], [12]. opined that increased availability of ART services led to the longevity of life, hence increased desire of children. The improvement of the immunity of the women living with HIV (WLHIV) and prolonged use of ART fertility desires tend to be reignited in Sub-Saharan Africa [13], [14].

The age, parity, economic status, and the number of surviving children play a great role in predicting the fertility desires among women living with HIV [11]. In 2015, the Kenya HIV estimate report indicated that about 79,000 women living with HIV needed Prevention of mother-tochild transmission (PMTCT) services by 2015 [15]. With UNAIDs - a program on HIV/AIDS - a public approach to test and treat, this figure of HIV positive women might increase. In search of the biological child came with its complexities such as disclosing the individual status to more people breaching confidentiality and continuum of care [16]. District Health Information System (DHIS) in 2018 had recorded that about 25,100 women living with HIV accessed ART [17].

In Kakamega County, the trend of women getting pregnant while knowing their status has been on the rise. In 2017, known HIV positive women attending antenatal care were 1,279 Busia 1,076, Bungoma 771 and Vihiga 401 and Nandi County reported 242 [17]. Kakamega County has been leading compared to other counties in the western Kenya region that share similar socio-cultural factors, and economical characteristics. With a more efficacious ART regiment and increase in ART uptake, there has been an increase in women seeking ANC services as in the case of Kakamega county [17]. Maternal to child HIV transmission (MTCT) stands at $10.8 \%$ by 2018, [18]. Mother to child transmission of HIV account for over $90 \%$ of HIV infection among children (PMTCT guidelines 2016). Kakamega County has in the recent past witnessed an increase in the number of new HIV positive individuals, there was a $41 \%$ increment of women living with HIV seeking antenatal care services between 2015 and 2018, [19].

\section{Statement of the Problem}

The human immunodeficiency virus has a negative life expectation when the intervention is not taken in time to the sex partner and the fetus and or child. Generally, mother to child transmission of HIV accounts for over $90 \%$ of HIV infection among children and infant or child deaths are at an all-time high. In 2018, mother to child HIV transmission in Kakamega health facilities was at about eleven per cent, but only from health facilities records. Women accessing antiretroviral treatment has improved in Kakamega County health facilities that might have promoted desire by these women to sire their biological children. However, currently, this information is inadequate and little is known about the fertility desires predicting pregnancy among women living with HIV. The current ART guideline 2018 is silent on the socio-cultural and societal factors predicting HIV positive women increased desire for pregnancy. Yes, Kakamega County saw a four-year increment in the numbers of new HIV positive women (41\%) seeking antenatal care services (20152018). Previously there were no specific studies in Kakamega to find out why known HIV positive women desire for pregnancy increased in relation to the sociodemographic factors. This backdrop led to the research to fill the gap.

\section{CONCEPTUAL FRAMEWORK}

\begin{tabular}{|c|c|}
\hline $\begin{array}{l}\text { Independent Variables } \\
\text { Sociodemographic } \\
\text { Age, education, } \\
\text { economic status } \\
\text { Community/Societal } \\
\underline{\text { demand }} \\
\text { Stigma due to } \\
\text { childlessness } \\
\text { Need to satisfy } \\
\text { communal norms }\end{array}$ & $\begin{array}{l}\text { Dependent Variables } \\
\text { Good virological } \\
\text { suppression } \\
\text { Improved HIV } \\
\text { Symptomatology } \\
\text { Improved quality of life } \\
\text { Prolonged life } \\
\text { Age, education, economic } \\
\text { status }\end{array}$ \\
\hline & $\begin{array}{l}\text { Outcome } \\
\text { Pregnancy }\end{array}$ \\
\hline
\end{tabular}

Fig. 1. Conceptual framework.

\section{Methods AND MATERIALS}

The study employed a descriptive cross-sectional research design. The design was flexible in describing the sociodemographic predictors of pregnancy among known HIV positive women in Kakamega County. The study area was Kakamega County with a focus on the sub-county health facilities. The study targeted women of reproductive age (1549) years on antiretroviral treatment (ART) for at least twelve months, however focused on (18-49) years due to legal age to consent. Furthermore, the women were already enrolled in comprehensive care clinics. Key informants comprised health care workers from the participating facilities because they were knowledgeable about HVI/AIDS programming. The study area had a target population of 1,591 known HIV positive women attending sub-county health facilities in Kakamega County. Simple random sampling was used to determine the sample size for this study of 319 whose data was collected using structured questionnaires and focus group discussion guides. Purposive sampling was used to select key informants, and systematic sampling was sued to select subcounty hospitals. The recruited research assistant was trained for two days and went to the field to assist in data collection on factors influencing pregnancy among known HIV positive 
women in Kakamega County.

The collected data were coded and entered into analysis software - Statistical package for social sciences (SPSS) version 25. Descriptive statistics were presented in proportionate tables. Key informant data triangulated the quantitative data in a narration format. Ethical clearance was obtained from the Institutional Ethics and Review Committee of Masinde Muliro University of Science and Technology and the permit from the National Commission for Science, Technology, and Innovation.

\section{RESULtS}

According to the HIV positive women surveyed (Table I), $54.8 \%$ of the known HIV positive women were aged above 35 years. Formal education acquisition by the HIV positive women was at $95 \%$. The study being from a Luhya dominated county, the Luhya community made $78.1 \%$ of the sample size. the survey indicated that $60.2 \%$ of the women were married. Moreover, $83.4 \%$ of the women were in informal employment. About parity, $79.9 \%$ of the women surveyed had two or more children. Christianity was the dominant religion making $78.9 \%$. At the time of the assessment, only $39.8 \%$ of the surveyed women were pregnant. It was established that $60.6 \%$ did not have medical insurance cover. It was important to understand the age and education level of the spouses to ascertain predictors of pregnancy among known HIV positive women; thus, $87.1 \%$ of the spouses were aged above 35 years; $73.8 \%$ had formal education.

\begin{tabular}{|c|c|}
\hline Sociodemographic characteristics & Percent \\
\hline \multicolumn{2}{|l|}{ Age } \\
\hline$<35$ Years & 45.2 \\
\hline$>35$ Years & 54.8 \\
\hline \multicolumn{2}{|l|}{ Education status } \\
\hline Formal & 95.0 \\
\hline No formal & 5.0 \\
\hline \multicolumn{2}{|l|}{ Ethnicity } \\
\hline Luhya & 78.1 \\
\hline Others & 21.9 \\
\hline \multicolumn{2}{|l|}{ Marital Status } \\
\hline Single & 39.8 \\
\hline Married & 60.2 \\
\hline \multicolumn{2}{|l|}{ Employment status } \\
\hline Formal & 16.6 \\
\hline Informal & 83.4 \\
\hline \multicolumn{2}{|l|}{ Parity } \\
\hline 1 & 20.1 \\
\hline$>1$ & 79.9 \\
\hline \multicolumn{2}{|l|}{ Insurance for your medical bill } \\
\hline Insured & 39.4 \\
\hline Not insured & 60.6 \\
\hline \multicolumn{2}{|l|}{ Religion } \\
\hline Christian & 78.9 \\
\hline Muslim and others & 21.1 \\
\hline \multicolumn{2}{|l|}{ Pregnancy Status } \\
\hline Yes & 39.8 \\
\hline No & 60.2 \\
\hline \multicolumn{2}{|l|}{ Age of your spouse } \\
\hline$<35$ Years & 12.9 \\
\hline$>35$ Years & 87.1 \\
\hline \multicolumn{2}{|l|}{ Education status of the spouse } \\
\hline Formal & 73.8 \\
\hline No formal & 26.2 \\
\hline
\end{tabular}

The data were presented in percentages (\%); n, 319 .

According to surveyed HIV positive women Focus Group Discussion, it was stated that:
1. ...the outcome of marriages are children; therefore, the HIV positive woman is required to have a biological child just like any other woman.

2. ... In some families, a boy child is valued more than a girl child thus an HIV positive woman is compelled by circumstance to keep on getting pregnant in order to birth a baby boy.

3. Key informant interviews conducted triangulated the findings from the surveyed HIV positive women, which stated that:

4. ... Women living with HIV in their reproductive age become pregnant purposefully to have a normal life like any other negative woman in society.

According to the HIV positive women survey, 55.8\% stated that society influenced the number of children a woman whether HIV positive. It was stated by $63 \%$ that the spouse had influence and was involved in pregnancy. This study also found out that $52 \%$ of the women surveyed acknowledged that the community held a negative perception of childless women, especially HIV positive women. It was revealed by $66.8 \%$ of the surveyed women that the community members did not attach value and pride over the childless HIV positive women; the community would chase them away as outcasts.

TABLE II: SOCIO-CULTURAL AND SOCIETAL DEMAND ON HIV POSITIVE WOMEN IN KAKAMEGA COUNTY

\begin{tabular}{lc}
\hline \hline Socio-cultural and societal demands & Percent \\
\hline \hline Societal influence on a number of children & \\
Yes & 55.8 \\
No & 44.2 \\
Spouse involved or influenced pregnancy & 63.0 \\
Yes & 37.0 \\
No & 52.0 \\
Communal beliefs on childless women & 48.0 \\
$\quad$ Cursed & 66.8 \\
Should be chased & 33.2 \\
Community regard barren women & \\
$\quad$ Not regarded as very important & As an outcast
\end{tabular}

According to the Focus Group Discussion forum, it was stated by members that:

1. ... Community expects positive women not to get pregnant. However, it should treat HIV positive women equal to those HIV negative women and sire children because their treatment guarantees an HIV negative child.

2. ... Some community members are fond of discriminating against childless HIV positive women, which is not fair to them and their families. 'siwezi kwenda chama kwani nitaitwa mama nani?' translated as 'I cannot attend women meeting; I will be addressed as whose mother?

\section{A. HIV Information of the HIV Positive Women}

According to the surveyed known HIV women (Table III), it was stated that $67.1 \%$ of the women had their first test of HIV status in 2015 and onwards. It was also stated that $98.4 \%$ of the tested women disclosed their HIV status to family members and friends. HIV tests being periodic to understand the viral loads, $73.7 \%$ were testing on or before six months; thus, $88.7 \%$ of the surveyed women had the viral load below 1,000. It was also reported that $97.5 \%$ knew about HIV transmission; with $91.8 \%$ knowing HIV transmission to a foetus/child. With increased campaigns and anti-stigmatism, $92.5 \%$ of the infected women were free to discuss fertility issues with healthcare workers; $88.7 \%$ of them were satisfied 
with the services received at the health facilities. As a protective measure against the spread or transfer of HIV from mother to child, $84.3 \%$ of them stated that they gave their children prophylaxis.

TABLE III: HIV INFORMATION

\begin{tabular}{|c|c|}
\hline HIV Information of the participants & Percent \\
\hline \multicolumn{2}{|l|}{ Date tested for HIV for the first time } \\
\hline$=<2015$ & 32.9 \\
\hline$>2015$ & 67.1 \\
\hline \multicolumn{2}{|l|}{ HIV Status } \\
\hline Disclosed & 98.4 \\
\hline Not disclosed & 1.6 \\
\hline \multicolumn{2}{|l|}{ ART regimen you use } \\
\hline $\mathrm{AZT} / 3 \mathrm{TC} / \mathrm{EFV}$ & 14.1 \\
\hline $\mathrm{TDF} / 3 \mathrm{TC} / \mathrm{DTG}$ & 22.3 \\
\hline $\mathrm{AZT} / 3 \mathrm{TC} / \mathrm{NVP}$ & 15.7 \\
\hline $\mathrm{TDF} / 3 \mathrm{TC} / \mathrm{NVP}$ & 6.9 \\
\hline $\mathrm{TDF} / 3 \mathrm{TC} / \mathrm{EFV}$ & 25.4 \\
\hline AVONZA & 15.7 \\
\hline \multicolumn{2}{|l|}{$\begin{array}{l}\text { When was the last time you tested your viral } \\
\text { load }\end{array}$} \\
\hline $0-6$ months & 73.7 \\
\hline$>6$ months & 26.3 \\
\hline \multicolumn{2}{|l|}{ The results } \\
\hline$<1,000$ & 88.7 \\
\hline$>=1,000$ & 11.3 \\
\hline \multicolumn{2}{|l|}{ Do you know how HIV is transmitted } \\
\hline Yes & 97.5 \\
\hline No & 2.5 \\
\hline \multicolumn{2}{|l|}{ Educated on HIV transfer to the child } \\
\hline Yes & 91.8 \\
\hline No & 8.2 \\
\hline \multicolumn{2}{|l|}{$\begin{array}{l}\text { Discussed fertility desire with a health care } \\
\text { provider }\end{array}$} \\
\hline Yes & 92.5 \\
\hline No & 7.5 \\
\hline \multicolumn{2}{|l|}{ Satisfied with the services } \\
\hline Yes & 88.7 \\
\hline No & 11.3 \\
\hline \multicolumn{2}{|l|}{ Prophylaxis used } \\
\hline Yes & 84.3 \\
\hline No & 15.7 \\
\hline
\end{tabular}

B. Reproductive information among the known HIV positive women in Kakamega County

According to surveyed known HIV positive women in Table IV, 94\% of the women visited health facilities. It was established that $79.9 \%$ of these pregnant HIV positive women delivered from a health facility; with $85.3 \%$ of the delivery being vaginal and only $14.7 \%$ being Caesarean section. It was established from the surveyed women that $89 \%$ delivered live babies. Moreover, $80.3 \%$ had delivered more than once as alluded to in Table I on parity. The age of the first pregnancy was established that $58 \%$ had their first experience beyond the age of 20 years. The $87.5 \%$ of the surveyed women preferred an ideal family size of at least three children. At the time of the assessment, $62.1 \%$ of the surveyed women were planning for more children.

According to surveyed HIV positive women Focus Group Discussion, it was stated that:

1. ... Every HIV positive person has a right to treatment (ARV's), HIV testing, health education, procreation, not to be discriminated against and the right to the family.

2. Key informant interviews triangulation stated as follows:

3. ... the efficacy of ARVs' has promoted pregnancy among HIV positive women

4. ... To some extent, family planning fails and results in a

pregnancy that was not planned for.

5. ...there is a relationship between delivery outcome and the number of children an HIV positive woman will have.

TABLE IV: REPRODUCTIVE INFORMATION OF THE HIV POSITIVE WOMEN

\begin{tabular}{|c|c|}
\hline Reproductive information & Percent \\
\hline \multicolumn{2}{|l|}{ Visited health facility } \\
\hline Yes & 94.0 \\
\hline No & 6.0 \\
\hline \multicolumn{2}{|l|}{ Place of delivery } \\
\hline Facility & 79.9 \\
\hline Home & 20.1 \\
\hline \multicolumn{2}{|l|}{ Mode of delivery } \\
\hline Vaginal & 85.3 \\
\hline Caesarean section & 14.7 \\
\hline \multicolumn{2}{|l|}{ Outcome of delivery } \\
\hline Live baby & 89.0 \\
\hline Succumbed baby & 11.0 \\
\hline \multicolumn{2}{|l|}{ Pregnancy frequency } \\
\hline Once & 19.7 \\
\hline Twice and more & 80.3 \\
\hline \multicolumn{2}{|l|}{ Age for the first pregnancy } \\
\hline$=<20$ Years & 42.0 \\
\hline$>20$ Years & 58.0 \\
\hline \multicolumn{2}{|l|}{$\begin{array}{l}\text { What is the ideal family size of } \\
\text { children? }\end{array}$} \\
\hline $1-2$ & 12.5 \\
\hline$=>3$ & 87.5 \\
\hline \multicolumn{2}{|l|}{ Preferred number of children } \\
\hline $1-2$ & 22.6 \\
\hline$=>3$ & 77.4 \\
\hline \multicolumn{2}{|l|}{ Planning for more children } \\
\hline Yes & 62.1 \\
\hline No & 37.9 \\
\hline
\end{tabular}

The results were presented in proportions (\%) of the respondents; $n, 319$.

\section{1) Contraceptive information}

According to the survey of HIV positive women (Table V), $94 \%$ of the women knew about the existing family planning methods. According to these women, $53.9 \%$ of the family planning methods used were pills, injectables and male condoms; $70.2 \%$ of these women utilized family planning. About $69 \%$ of the spouses of the surveyed women had approved the use of family planning methods.

TABLE V: CONTRACEPTIVE INFORMATION

\begin{tabular}{lc}
\hline \hline \multicolumn{1}{c}{ Contraceptives } & Per cent \\
\hline Knowledge of family planning methods & 94.0 \\
Yes & 6.0 \\
No & \\
Types of family planning methods & 0.6 \\
Female sterilization & 6.6 \\
Pill & 0.9 \\
IUD & 11.6 \\
Injectable & 6.3 \\
Implants & 2.5 \\
Male condoms & 53.9 \\
Pills, Injectable and Male condom & 0.9 \\
Pills, Injectable, implant and Male condom & \\
Pills, IUD, Injectables, Male condoms, female & 7.5 \\
condoms, withdrawal emergency & 1.9 \\
contraception & \\
Pills, Male and female condoms & 70.2 \\
Using the family planning method? & 29.8 \\
Yes & \\
No & 69.0 \\
Husband/Partner approved the use of family & 31.0 \\
planning & \\
Yes & \\
No & \\
\hline \hline The results were presented in proportions (\%) of the respondents; $\mathrm{n}, 319$
\end{tabular}


According to the HIV positive women Focus Group Discussion forum, it was stated that:

1. ... the most common methods of family planning used by sub-county health facilities were implants, Jadel, pills, IUD, depo, and condoms (mostly male condoms).

The researcher computed a bivariate analysis to determine the status of the association between the socio-cultural and societal demand with the pregnancy status of the participants. The crosstab results showed that there was a statistically significant relationship between sociodemographic characteristics of the participants and the societal influence on the number of children, $\mathrm{p}<0.001$; spouse involvement/influence on pregnancy, $\mathrm{p}<0.001$; community beliefs on childless women, $\mathrm{p}<0.001$; and community regard of childless women, $\mathrm{p}<0.001$. The Odds Ratio showed a decreasing association between socio-cultural and societal demand and pregnancy status, societal influence on a number of children $(\mathrm{OR}=0.29 ; 95 \% \mathrm{CI}\{0.23-0.36\})$; spouse involved or had influence on pregnancy $(\mathrm{OR}=0.37 ; 95 \%$ CI $\{0.31-$ $0.44\})$; community beliefs on childless women, $(\mathrm{OR}=0.24$; $95 \% \mathrm{CI}\{0.18-0.31\})$; and community regard barren women, $(\mathrm{OR}=0.41 ; 95 \%$ CI $\{0.38-0.48\})$.

TABLE VI: BIVARIATE ANALYSIS OF SOCIO-CULTURAL AND SOCIETAL DEMAND WITH THE PREGNANCY STATUS

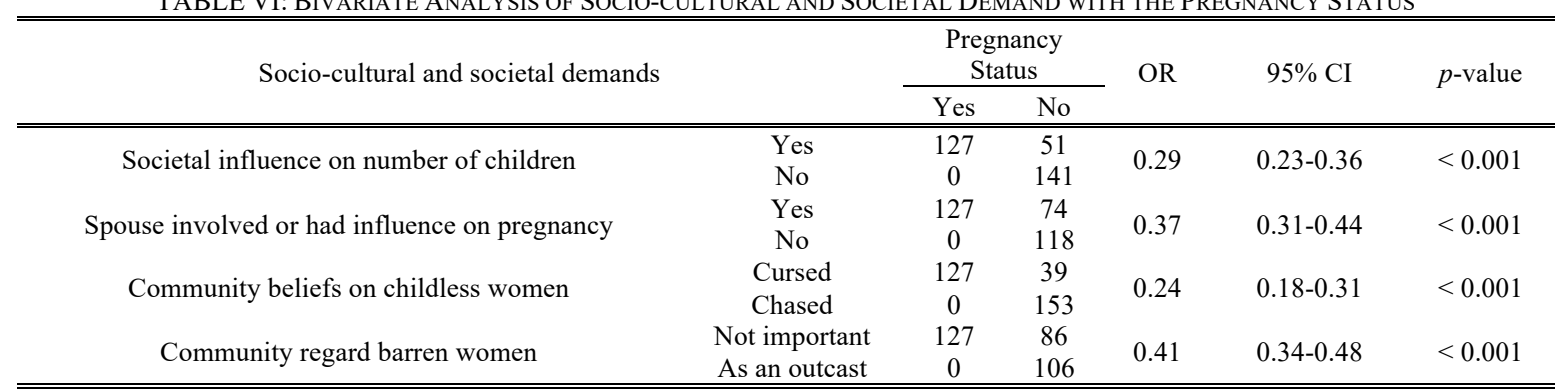

The results were presented in proportions (\%) of the respondents; $n, 319$.

\section{DISCUSSION}

The sociodemographic characteristics were essential determinants of increased pregnancy desires among HIV positive women in Kakamega County. The researcher's investigation on the sociodemographic characteristics showed that the HIV positive women attending health facilities were slightly above the youthful ages. This could be related to the study by [20] that the modal age group with a high prevalence of HIV in 2019 was 34-39 years. However, this trend is shifting towards modal ages of 24-29 leading to new infection cases as noted by [21]. The age among women is a predictor of pregnancy in relation to marriage and parity. Therefore, it was clear that surveyed HIV positive women were still active to sire children as per their fecundity; with at least two-thirds of them being in an active marriage. The Luhya community hold children in high regard, therefore, age, marital status and parity among women are of utmost importance in predicting pregnancy and parity among known HIV positive women. It was stated by the key informant that the outcome of marriage were children regardless of the HIV status; having a biological child is the apex of a marriage. This study is in line with [1] that age is a factor that influences pregnancy among women of all calibre and statuses in African society and even beyond African borders. The rush by the young HIV positive women in their reproductive stage is an indicator of their high affinity for procreation which diminishes with age as the biological clock comes to a halt a fact concurred by [9]. Every woman has an urge for a biological child, this study showed that the older women were present at heath facilities looking forward to a child. Moreover, the study found that older women were eagerly looking for a particular sex of a child especially a male child as a fact supported by [9]. More so majority knew of the family planning but still went ahead and tried conceiving. The young and energetic women though HIV positive and in marriage were predictors of pregnancy as a requirement to fulfil the marital function and identity. A previous study by
[7] was in agreement with this finding. This study states that with improvement in HIV symptomatology and prolonged and improved quality of life, HIV positive women will consider recovering the lost glory by attempting to conceive to prove their womanhood.

The level of education of the participants plays a critical role in exposing the individual to life manoeuvres and opportunities. The key informant interview showed that the level of education among the participants eliminated the vertical transmission of HIV to newborn babies. This was an important development that encouraged HIV positive women to desire their biological children. Education is the epitome of literacy and information about procreation, family, medication and development. A previous study by [22] stated that HIV positive women in sub-Saharan Africa had negative life outcomes for their progeny due to vertical transmission of HIV to their children. Lack of information about HIV and its transmission leads to many women falling victims of HIV vertical transmission. This study, however, stated that education contributed to increased uptake of family planning as well as increased desires to conceive and have a biological child or deliver a particular desired sex of a child. [2] add that education among women influenced their autonomy decision making on fertility intentions. HIV positive women can make independent decisions regarding pregnancy and childbearing as well as family planning.

The known HIV positive women surveyed engaged in informal economic activities, which was stated that give autonomy in pregnancy decision-making. Childbearing is the centerpiece of a family that holds the marriage together. Raising children demands a family to be economically empowered. Therefore, it was stipulated in this study that the known HIV positive women were financially stable and were thus able to have a biological child. [1], [5] concur with this study, that the income and the economic status of HIV positive women influence pregnancy. This would be indicated by the surveyed women having at least three children. 
From the hierarchical regression model, it is stated that sociodemographic variables (age, education, employment and parity were predictors of pregnancy among these known HIV positive women in Kakamega County.

The spousal and the community influence the number of children an HIV positive woman would have. However, the community had a negative perception of HIV positive women especially the childless ones. It is common that currently, HIV stigma is fading from the face of the earth. HIV positive individuals deserve fair treatment by the community just as the HIV negative ones. This study established that the continuity of the family lies with the community, a finding that concurs with [11] that stated that spousal and community support and approval were of grave importance to HIV positive women permission to sire their biological offspring, living a normal satisfying and fulfilling life. The spouses and community support heightens the positive energy among the HIV positive women in the society; lengthens life expectancy in addition to delivering HIV negative children when following the protective measures prescribed. This agreed with [13] that argued that the community's positive attitude and cultural beliefs on the infected and the affected women promote the existence and uptake of family planning and procreation potential of these HIV positive women. In reference to the hierarchical regression model, it was established that the community and societal demands had the greatest influence in the determination of pregnancy - stigma and need to satisfy the community. The community stigmatization and individual desires and demand among HIV women contribute significantly as predictors of pregnancy.

The study established that there was a belief by the community over the childless women which was attributed to the bad omen. Concerning HIV positive childless women, it was discovered that the community discriminated against them. Community demeaned childless women with some stating that such women were to be chased away as they were of no value to them. The community did not expect HIV positive women to get pregnant. This was a notion held by most community members suggesting that such women in their previous lives were promiscuous and did not deserve children; they were social misfits. It was established that societal influence over the number of children, the community's beliefs on childless women and the community's regard to childless women were influencers of pregnancy especially for those who were married. In this study the childless and HIV positive women were heartbroken even to participate in the women meetings; feared discrimination against the lack of a child's identity.

It was shown that there was a statistically significant association between socio-cultural and societal demand with pregnancy status, which meant that the socio-cultural and societal demand on HIV positive women influenced pregnancy. Culturally, women are expected to sire children to continue the family tree and inheritance as well. Parity among women as in this study HIV positive women is important to the society from which she is married. However, the Odds Ratio recorded a decreasing association of the socio-cultural and societal demand against pregnancy status; which meant that the society was $71 \%$ less likely to influence the number of children; the spouse was $63 \%$ less likely to influence pregnancy among HIV positive women; the community was
$76 \%$ less likely to believe that childless women were cursed, and the community had 59\% unlikelihood of regard, childless women, as not important.

\section{A. HIV Information of the HIV Positive Women}

Recent tests (between January 2020 and November 2020) of the viral load by these HIV positive women indicated that most of them had low detectable levels. This test sought to establish the efficacy of the regimen as well as pregnancy prediction among these women. It was also established that these HIV positive women were aware of the transmission of HIV thus were able to manage it. This could be attributed to improved health systems as also affirmed by [23].

The healthcare workers were friendly and welcoming thus facilitating the exchange of knowledge regarding HIV management. This is in line with this study where it was established that the healthcare workers encouraged discussion over fertility desires among these HIV positive women. This kind of approach satisfied most of these women. However, before advancement in healthcare provision, most HIV positive women lived in denial and continued to shift blame exposing unborn infants to HIV infection. Besides, these women lacked adherence to treatment and increased risks to infants as connoted by [24].

The health care workers promoted confidence among the HIV positive women thus leading to an increased desire for pregnancy. The women were taught about the usage of prophylaxis to their newborns averting HIV infections. [25] noted that there are infants missing prophylaxis at birth, this exposes the infants to a higher risk of HIV infection. Increased desires for pregnancy among HIV positive women in Kakamega County are an indicator that the health facilities provide infants with prophylaxis at birth to prevent the transmission of the infection.

\section{B. Reproductive Information of the HIV Positive Women}

This study stated that HIV positive women had skilled birth attendance, which was important as their deliveries needed skilled midwives to manage and prevent mother to child infections as well as health complications arising from delivery altogether. In the recent past before family planning among known HIV positive women was introduced, with the integration of family planning in the comprehensive clinic, pregnancy among these women has been reported despite the intervention. This calls for more capacity building on health care workers and education to the women on the best timing of the pregnancy for better results. This was in support of [13] study that elicited that most HIV positive pregnant women must endeavour to solicit hospital attention during parturition. It was also found that most of these women delivered naturally - vaginal delivery -delivering live babies. This study shows that the outcome of marriage in the African perspective are children, which means that even HIV positive women are culturally required to sire children.

Women fecundity has a time limit that runs from twelve years to about forty-five years where most of them reach menopause. It was, therefore, established that most of these HIV positive women had their first pregnancy between the ages of fifteen years to twenty-five years. With the advancement in HIV/AIDS medication that promotes family planning and childbearing, it is always critical for HIV 
positive women to try and bear biological children of their own once they are still within the fertile period.

Age for the first time of pregnancy informs the need to have a child or children of all sexes while still within the permissible biological clock that does not compromise their health. This was supported by [26], where it was connoted that fertility desire among women globally stood at 59\% with [14] revealing that women in sub-Saharan Africa desire children as ART treatment and survival rates improve. In this study majority of these women were virally suppressed and this meant the resumption of proper physiological functions with improved fertility leading to an urge to get pregnant. [27] concur with the study that young HIV positive women needed much support on pregnancy decisions to sire healthy children and live healthier lives. Also, the study found that most of these women preferred an ideal family size of three to four children. Therefore, there was a relationship between the delivery outcome to the number of children. It was worth noting that most of these HIV positive women became pregnant regardless of their health status because it was their choice with a few noting that the family planning methods failed and hence became pregnant. To some extent, it was established that these women became pregnant because they reserved the right to have a normal life just like HIV negative women in society.

According to [22], culturally in Africa, one is not complete without a biological child(ren). Nevertheless, these women indicated that they became pregnant because they planned with the spouse over the issue; with the majority of them adhering to antenatal care clinic visits. This could be drawn from a study by [22], [16], who stated that previously HIV positive used to become pregnant without their planning which has in the recent past changed where the partners plan together over the pregnancy. Additionally, every HIV positive woman globally has a right to become pregnant a right to procreation and a right to the family. According to [17], Kakamega County has seen a rise of HIV positive women getting pregnant knowingly with increased attendance in the antenatal care clinic.

\section{Contraceptives Information of the HIV Positive Women}

This study stated that HIV positive women had skilled birth attendance, which was important as their deliveries needed skilled midwives to manage and prevent mother to child infections as well as health complications arising from delivery altogether. In the recent past before family planning among known HIV positive women was introduced, with the integration of family planning in the comprehensive clinic, pregnancy among these women has been reported despite the intervention. This calls for more capacity building on health care workers and education to the women on the best timing of the pregnancy for better results. This was in support of [13] study that elicited that most HIV positive pregnant women must endeavour to solicit hospital attention during parturition to ensure prevention of mother to child transmission of HIV optimized. It was also found that most of these women delivered naturally - vaginal delivery -delivering live babies. This study shows that the outcome of marriage in the African perspective are children, which means that even HIV positive women are culturally required to sire children.

Women fecundity has a time limit that runs from twelve years to about forty-five years where most of them reach menopause. It was, therefore, established that most of these HIV positive women had their first pregnancy between the ages of fifteen years to twenty-five years. With the advancement in HIV/AIDS medication that promotes family planning and childbearing, it is always critical for HIV positive women to try and bear biological children of their own once they are still within the fertile period.

\section{CONCLUSION}

Age, education level, marital status parity and economical status, medical cover influenced pregnancy among the known HIV positive women in Kakamega County. The HIV positive women visited health facilities for family planning services and education on HIV management. These women used skilled birth attendance during childbirth.

Socio-cultural and societal demands were predictors of pregnancy among known HIV positive women in Kakamega County. It was stated that the community should treat HIV positive women with respect and dignity, thus permitting them to continue their family legacy and sire children. Moreover, the community should stop mistreating childless HIV positive women and stop associating them with bad omen as social misfits.

\section{RECOMMENDATION}

To address the socio-cultural and societal demands, there is a need for the county government, department of health services to provide health education to the community on stigma reduction and discrimination meted on these women and negative perception of childlessness women in the society especially known HIV positive women. Further works on the myths and misconception that barrenness is blamed on women leaving men scot-free for the cloud to be the culprits of childlessness in the family.

With the UNAIDS test and treat strategy in managing HIV/AIDS currently being implemented worldwide, and in the country, there is a need to enhance structures and policies that support known HIV positive women through their age cohort, level of education and their economic status on pregnancy matters and childbearing.

\section{ACKNOWLEDGEMENT}

There were individuals who instrumental for the article who I wish to recognize; Dr Rose Olayo (PhD), Dr Mary Kipmerewo (PhD), Dr Benard Wesonga (PhD), Dr Maximila Wanzala $(\mathrm{PhD})$, Dr Okenwa Vincent Emmanuel $(\mathrm{PhD})$ and Mr John Arudo for supporting me academically and for their undivided attention and commitment. I also appreciate Dr Sabella Kiprono $(\mathrm{PhD})$ for reading through my work and walking with me step by step. I acknowledge support from my research assistant Mr Paul Kem for making this research a success. I appreciate my immediate family for their love, support and sacrifice. I thank the entire School of Graduate, University fraternity, and friends for providing unlimited motivation and an enabling environment to allow for the successful conclusion of this work. 
May the almighty God bless and richly reward you.

\section{REFERENCES}

[1] Kakaire O, Osinde MO, Kaye DK. Factors that predict fertility desires for people living with HIV infection at a support and treatment centre in Kabale, Uganda. Reproductive Health. 2010; 7(1): 1-6.

[2] Harrington EK, Newmann SJ, Onono M, Schwartz KD, Bukusi EA, Cohen CR, et al. Fertility intentions and interest in integrated family planning services among women living with HIV in Nyanza Province, Kenya: a qualitative study. Infectious Diseases in Obstetrics and Gynecology. 2012; 2012.

[3] Snow RC, Laski L, Mutumba M. Sexual and reproductive health: progress and outstanding needs. Global Public Health. 2015; 10(2): 149-73.

[4] Bogale YR. Fertility intention and use of contraception among women living with HIV in Adama Hospital Medical College, Ethiopia (Doctoral dissertation).

[5] Kuete M, Yuan H, Kemayou AL, Songo EA, Yang F, Ma X, et al. Scale up use of family planning services to prevent maternal transmission of HIV among discordant couples: a cross-sectional study within a resource-limited setting. Patient Preference and Adherence. 2016; 10: 1967.

[6] Agbo S, Rispel LC. Factors influencing reproductive choices of HIV positive individuals attending primary health care facilities in a South African health district. BMC Public Health. 2017; 17(1): 1-9.

[7] Cuinhane CE, Roelens K, Vanroelen C, Quive S, Coene G. Perceptions and decision-making with regard to pregnancy among HIV positive women in rural Maputo Province, Mozambique-a qualitative study. BMC Women's Health. 2018; 18(1): 1-21.

[8] Gutin SA, Namusoke F, Shade SB, Mirembe F. Fertility desires and intentions among HIV-positive women during the post-natal period in Uganda. African Journal of Reproductive Health. 2014; 18(3): 67-77.

[9] Asfaw HM, Gashe FE. Fertility intentions among HIV positive women aged 18-49 years in Addis Ababa Ethiopia: a cross-sectional study. Reproductive Health. 2014; 11(1): 1-8.

[10] Iwelunmor J, Newsome V, Airhihenbuwa CO. Framing the impact of culture on health: a systematic review of the PEN-3 cultural model and its application in public health research and interventions. Ethnicity \& Health. 2014; 19(1): 20-46.

[11] Ayieko J, Ti A, Hagey J, Akama E, Bukusi EA, Cohen CR, et al. HIV status and treatment influence on fertility desires among women newly becoming eligible for antiretroviral therapy in western Kenya: insights from a qualitative study. Reproductive Health. 2017; 14(1): 1-9.

[12] Wanyenze RK, Matovu JK, Kamya MR, Tumwesigye NM, Nannyonga M, Wagner GJ. Fertility desires and unmet need for family planning among HIV infected individuals in two HIV clinics with differing models of family planning service delivery. BMC Women's Health. 2015; 15(1): 1-2.

[13] Mohammed F, Assefa N. Determinants of desire for children among HIV-positive women in the Afar Region, Ethiopia: case control study. Plos One. 2016; 11(3): e0150566.

[14] Mayhew SH, Colombini M, Kimani JK, Tomlin K, Warren CE, Mutemwa R. Fertility intentions and contraceptive practices among clinic-users living with HIV in Kenya: a mixed methods study. BMC Public Health. 2017; 17(1): 1-5.

[15] Republic of Kenya. Kenya HIV Estimates. National AIDS and STI Control Programme. 2015. http://nacc.or.ke/wpcontent/uploads/2016/12/Kenya-HIV-Estimates-2015.pdf retrieved on 28th September 2021.

[16] Inyangala H, Makwali JA, Aluku S. Factors influencing pregnancy decision making among known HIV-positive women of reproductive age in Bosia County, Kenya. Journal of Pregnancy and Child Health. 2016; 3(5).

[17] Demographic Health Information System. Health Information System Indicators, Kenya. https://www.measureevaluation.org/hisstrengthening-resource-center/country-profiles/kenya-1.

[18] Republic of Kenya. Kenya HIV Estimates. National AIDS and STI Control Programme. 2018. https://nacc.or.ke/wpcontent/uploads/2018/12/HIV-estimates-report-Kenya-20182.pdf retrieved on 28th September 2021.

[19] District Health Information System 2 (DHIS2). https://www.openhealthnews.com/resources/district-healthinformation-system-2-dhis2.

[20] Cambiano V, Johnson CC, Hatzold K, Terris-Prestholt F, Maheswaran $\mathrm{H}$, Thirumurthy $\mathrm{H}$, et al. The impact and cost-effectiveness of community-based HIV self-testing in sub-Saharan Africa: a health economic and modelling analysis. Journal of the International AIDS Society. 2019; 22: e25243.

[21] Mwango LK, Stafford KA, Blanco NC, Lavoie MC, Mujansi M, Nyirongo N, Tembo K, Sakala H, Chipukuma J, Phiri B, Nzangwa C. Index and targeted community-based testing to optimize HIV case finding and ART linkage among men in Zambia. Journal of the International AIDS Society. 2020 Jun;23:e25520.

[22] Kimani J, Warren C, Abuya T, Mutemwa R, Mayhew S, Askew I Family planning use and fertility desires among women living with HIV in Kenya. BMC Public Health. 2015; 15(1): 1-10.

[23] Rositch AF, Gravitt PE, Smith JS. Growing evidence that HPV infection is associated with an increase in HIV acquisition: exploring the issue of HPV vaccination. 2013; 357.

[24] Rucinski KB, Powers KA, Schwartz SR, Pence BW, Chi BH, Black V, et al. Longitudinal patterns of unmet need for contraception among women living with HIV on antiretroviral therapy in South Africa. PLoS One. 2018; 13(12): e0209114.

[25] Feucht UD, Meyer A, Kruger M. Missing HIV prevention opportunities in South African children-a 7-year review. BMC Public Health. 2014; 14(1): 1-8.

[26] Yeatman S, Eaton JW, Beckles Z, Benton L, Gregson S, Zaba B. Impact of ART on the fertility of HIV-positive women in sub-Saharan Africa. Tropical Medicine \& International Health. 2016; 21(9): 10711085.

[27] Tanner AE, Song EY, Mann-Jackson L, Alonzo J, Schafer K, Ware S, et al. Preliminary impact of we Care social media intervention to support health for young men who have sex with men and transgender women with HIV. AIDS Patient Care and STDs. 2018; 32(11): 450458.

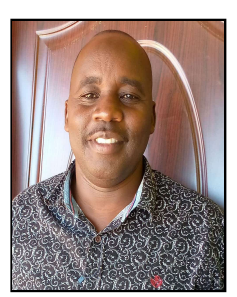

I. Maru was Born in Maendeleo village Matunda sub-location Matunda location in Soy sub-county Usain-Gishu County Kenya on 10th October 1973. He attained a master of public health biostatistics and population health Masinde Muliro University of science and technology Kenya 2021; Bachelors of Community Health and Development Great Lakes University Kisumu 2013; Higher Diploma in Community Health and Development Great Lakes University Kisumu 2012 and Diploma in clinical medicine and surgery Kenya medical training college Kisumu 2002. He has a wealth of knowledge and experience in HIV management after starting his HIV career in 2005 where he worked for Medisin san frontees, Kemri -CDC, Elizabeth glazer pediatric aids foundation, Path Kenya and Ampath plus Program in Kakamega County. Isaac is a member of the Kenya clinical officers' association (KCOA) and a practising Christian 